\title{
Vitiated high Karlovitz n-decane/air turbulent flames: Scaling laws and micro-mixing modeling analysis
}

\author{
Alexandre Bouaniche • Nicolas Jaouen • \\ Pascale Domingo • Luc Vervisch
}

Received: date / Accepted: date

\begin{abstract}
Turbulent flames with high Karlovitz numbers have deserved further attention in the most recent literature. For a fixed value of the Damköhler number (ratio between an integral mechanical time and a chemical time), the increase of the Karlovitz number (ratio between a chemical time and a micro-mixing time) by an order of magnitude implies the increase of the turbulent Reynolds number by two orders of magnitude [10. In the practice of real burners featuring a limited range of variation of their turbulent Reynolds number, high Karlovitz combustion actually goes with a drastic reduction of the Damköhler number. Within this context, the relation between the dilution by burnt gases and the apparition of high Karlovitz flames is discussed. Basic scaling laws are reported which suggest that the overall decrease of the burning rate due to very fast mixing can indeed be compensated by the energy brought to the reaction zone by burnt gases. To estimate the validity of these scaling laws, in particular the response of the quenching Karlovitz versus the dilution level with a vitiated stream, the micro-mixing rate is varied in a multiple-inlet canonical turbulent and reactive micro-mixing problem. A reduced n-decane/air chemical kinetics is used, which has been derived from a more detailed scheme using a combination of a directed relation graphs analysis with a Genetic Algorithm. The multiple-inlet canonical micro-mixing problem includes liquid fuel injection and dilution by burnt gases, both calibrated from conditions representative of an aeronautical combustion chamber. The results confirm the possibility of reaching, with the help of a vitiated mixture, very high Karlovitz combustion before quenching occurs.
\end{abstract}

A. Bouaniche ${ }^{\star} \cdot$ N. Jaouen ${ }^{\star}++$. P. Domingo ${ }^{\star} \cdot$ L. Vervisch ${ }^{\star}$

${ }^{\star}$ CORIA - CNRS, Normandie Université, INSA de Rouen Normandie, France.

+ Present address: Heat-Transfer \& Reacting Flows, Royal Institute of Technology, Stockholm, Sweden

E-mail: vervisch@coria.fr 
Keywords High Karlovitz combustion; Kerosene reduced chemistry; n-decane flame; micro-mixing modeling; Large Eddy Simulation; Spray flame

\section{Introduction}

In the quest for combustion systems with high fuel-efficiency, the strong increase of the turbulence intensity has recently seen a renewed interest 115.9

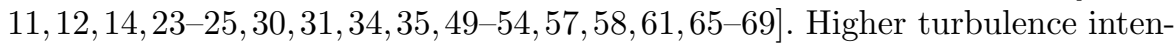
sity is expected to favour enhanced micro-mixing of the reactants, followed by a higher volumetric burning rate. In his seminal works, Karlovitz [31 noted that flames can be 'arrested by high velocity gradients and strong velocity fluctuations'. Such flame quenching by intense turbulence was examined under various conditions. One of the first experimental observation concluded that above a critical value of the number $K=\left(\delta_{\mathrm{L}} / S_{L}\right)\left(u^{\prime} / \ell_{\mathrm{T}}\right)$, ratio between a chemical time and a mechanical time, of the order of a few tenth [13, combustion propagating in fresh gases cannot be sustained. $u^{\prime}$ denotes the rms turbulent velocity, $\ell_{\mathrm{T}}$ is the integral scale of turbulence, $\delta_{\mathrm{L}}$ the laminar flame thickness and $S_{L}$ the laminar burning velocity. Results which immediately triggered further discussions on the exact definition of the characteristic scales chosen to measure $K$ 32].

Along the same lines, the phenomenological analysis of the structure of turbulent flames initiated by Borghi 6], was followed by the development of combustion regime diagrams 7, 47, 48, , built from Damköhler and Karlovitz numbers and additional ratios of times and length scales characteristic of the turbulence and the reaction zones. The Damköhler number is usually approximated as $D a=\tau_{\mathrm{T}} / \tau_{\mathrm{c}}$, where $\tau_{\mathrm{T}}$ is an integral mixing time and $\tau_{\mathrm{c}}$ a chemical time. The Karlovitz number relates to small-scale turbulent mixing, $\mathrm{Ka}=\tau_{\mathrm{c}} / \tau_{\mathrm{k}}$, with $\tau_{\mathrm{k}}$ the small-scale (Kolmogorov) mixing time [37], leading to the relation 10

$$
\mathrm{Da} \times \mathrm{Ka}=\frac{\tau_{\mathrm{T}}}{\tau_{\mathrm{k}}} \approx \operatorname{Re}_{\mathrm{T}}^{1 / 2},
$$

where $\operatorname{Re}_{\mathrm{T}}=u^{\prime} \ell_{\mathrm{T}} / \nu$ is the turbulent Reynolds number, with $\nu$ the kinematic viscosity of the fluid. Therefore, for a fixed value of Da at which combustion occurs, $\mathrm{Re}_{\mathrm{T}} \approx \mathrm{Ka}^{2}$, and increasing the Karlovitz number by, say a factor 10 , would mean increasing the turbulent Reynolds number by a factor 100. Such large increase of the turbulent Reynolds number cannot always be achieved. In practice, when Ka goes up, Da does go down in order to fulfil the relation (1). In fact, this approximate relation (1) suggests that, at very high Reynolds numbers $\left(\operatorname{Re}_{\mathrm{T}} \rightarrow \infty\right)$, chemistry can still be fast $(\mathrm{Da} \rightarrow \infty)$, as long as the chemical time scale is shorter (or of the order of) than the shortest flow time scale, i.e. the amplitude of Ka stays moderate. It is usually believed that this is the operating conditions of most practical combustion systems and it was the state of affair till around the year 2010. Over the last eight years however, studies have been published displaying an exponential growth of the Karlovitz number with years, see Fig. 1. As in the pioneer works reported 


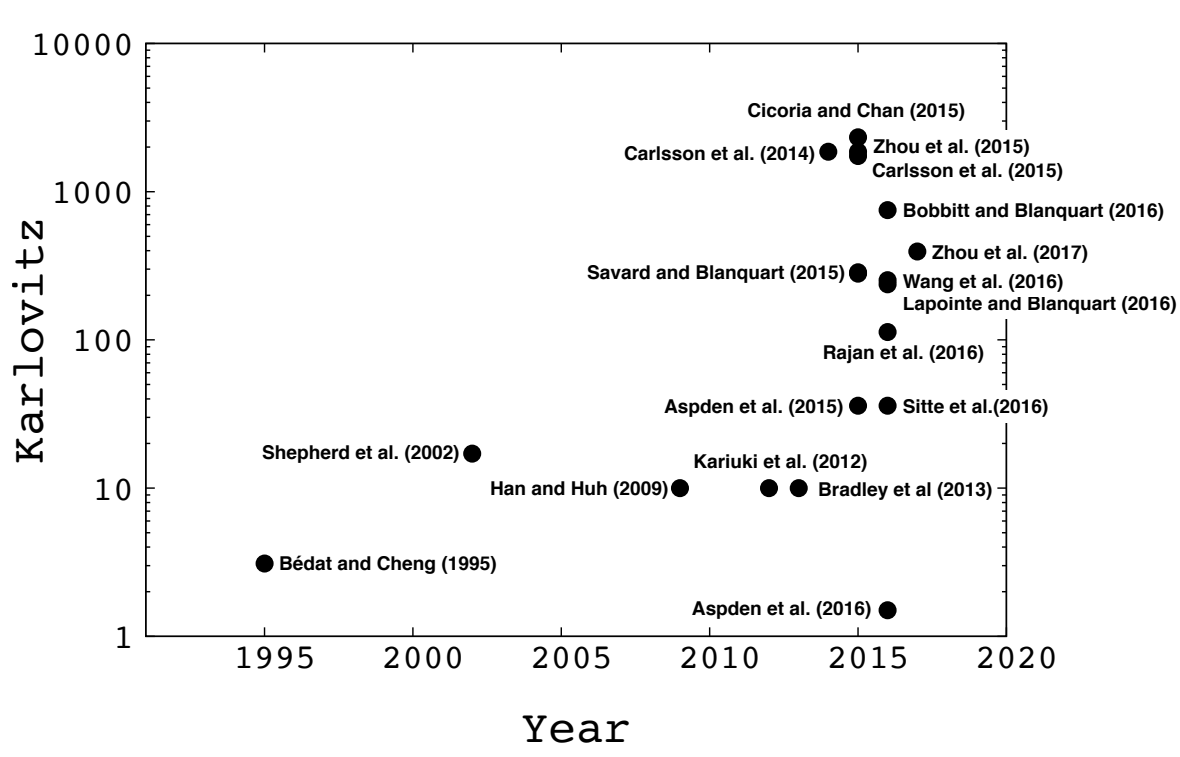

Fig. 1 Karlovitz numbers considered in a sample of the literature over the past 25 years.

above, the exact definition of Ka may differ from one study to the other, but the increase in $\mathrm{Ka}$ is large enough to be significant, whatever its exact definition. At the same time, the Damköhler number suffered from a drastic decrease of its amplitude (Fig. 2).

The flames at the highest Ka examined in the works of Fig. 1 were actually not 'self-sustained', but benefitted from a large reservoir of hot burnt gases, for instance a vitiated co-flow. These flames with very high values of the Karlovitz number (up to more than 1500), and thus very low values of the Damköhler numbers (down to 0.02), may eventually release less heat than they gain from burnt gases to maintain fuel oxidation. Nonetheless, all the fuel injected was burnt and thus high-Karlovitz combustion was achieved. This flame regime may be of interest locally in a combustion chamber, for instance to secure flame stabilisation in a highly turbulent flow zone. It is therefore legitimate to wonder by which mechanisms the dilution by burnt gases makes the flame more robust to high $\mathrm{Ka}$ (and low Da) and how the response of the quenching Karlovitz number scales versus the level of dilution by burnt gases. Among the numerous candidates, in the case of premixed combustion, an increase of the flame speed is a potential phenomenon and in the case of non-premixed systems, fast mixing with burnt gases may help local auto-ignition. At least three questions emerge from these preliminary remarks: (i) what is the basic scaling for flame speed including both dilution by burnt gases and Ka effect? (ii) In a non-premixed system, how much of recirculating burnt products must be included to secure high Ka combustion? (iii) What is the global scaling of $\mathrm{Ka}$ at quenching versus the dilution level of the fresh mixture with a vitiated stream. 


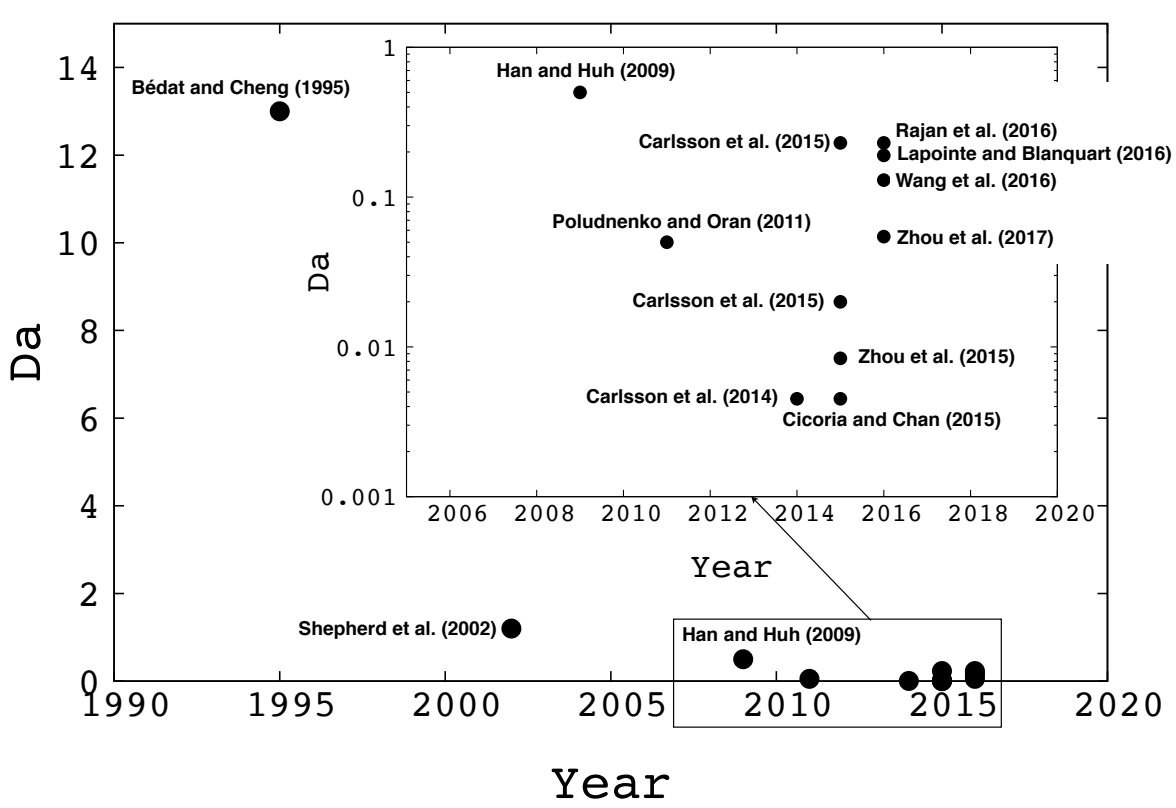

Fig. 2 Damköhler numbers considered in a sample of the literature over the past 25 years, with a zoom over most recent years.

In an attempt to answer these basic questions, simple scaling laws are proposed in this work combining premixed and non-premixed regimes. Simulations of micro-mixing/chemistry interaction are then performed to verify the trends. If the effect of turbulence is over-simplified through a basic stochastic mixing closure, the impact of spray evaporation and of $n$-decane detailed chemistry is included. To do so, a set of reduced chemical schemes is first derived for n-decane/air combustion, as reported in the next section. The elementary scaling relations for high Ka flame in vitiated stream are discussed in the subsequent section, before examining the response of n-decane/air combustion at high $\mathrm{Ka}$ in the final section.

\section{A fuel-spray stochastic micro-mixing canonical problem for high-Ka analysis}

Starting from a given set of initial conditions, representative of the streams feeding the reaction zones in an aeroengine, reference time evolutions of thermochemical quantities are constructed in a pseudo-reactor, combining the approaches discussed in 20,29. A set of $N_{\mathrm{P}}=1000$ stochastic particles are distributed at initial time according to the chemical composition of three inlets, containing either liquid kerosene, air or burnt gases. This last inlet mimics recirculation of burnt gases, as it would be observed in a swirled fuel injection. After the initialisation, evaporation of the liquid fuel occurs and the gas phase 
evolves at about 10 bars according to a stochastic mixing model to which the chemical sources of kerosene/air chemistry are added. The thermochemical properties of the particles vary following a procedure explained below, to generate synthetic turbulent distributions, as the scatter plot of temperature versus mixture fraction seen in Fig. 3. Various distributions will be obtained varying both the initial amont of burnt gases and a Karlovitz number constructed from the control parameters of the canonical problem.

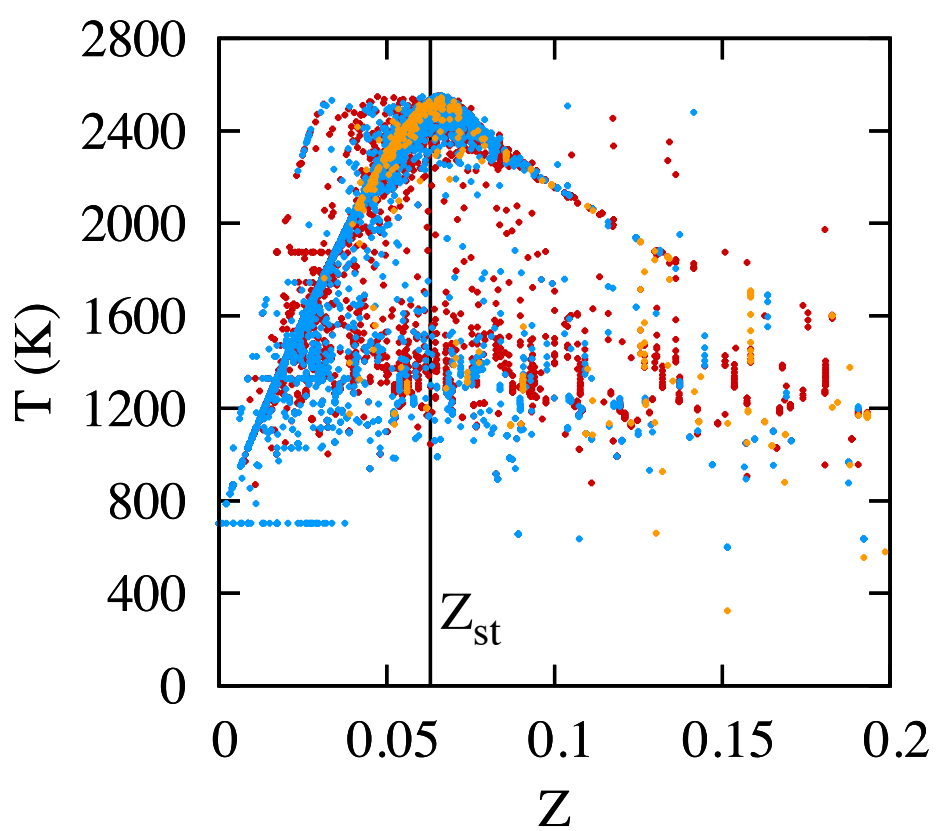

Fig. 3 Scatter plot of stochastic particles temperature $v s$ mixture fraction. Particles are coloured depending on their initial condition. Blue: air. Orange: kerosene. Red: burned gases. $\mathrm{Z}_{\text {st }}$ is the stoichiometric mixture fraction.

The number of stochastic particles initially set at the concentration and temperature of the $j$-th inlet $(j=1,2,3)$ is proportional to $\dot{Q}_{\mathrm{m}_{j}}$, the mass flow rate injected by this inlet,

$$
N_{P_{j}}=N_{\mathrm{P}} \times \frac{\dot{Q}_{\mathrm{m}_{j}}}{\dot{Q}_{\mathrm{m}}},
$$

where $\dot{Q}_{\mathrm{m}}=\dot{Q}_{\mathrm{m}_{1}}+\dot{Q}_{\mathrm{m}_{2}}+\dot{Q}_{\mathrm{m}_{3}}$ denotes the total mass flow rate. The liquid kerosene inlet at $T=450 \mathrm{~K}$ represents $2.3 \%$ of $\dot{Q}_{\mathrm{m}}\left(\dot{Q}_{\mathrm{m}_{1}}=0.023 \dot{Q}_{\mathrm{m}}\right)$. The mass flow rate of the air inlet at $T=703 \mathrm{~K}$ is $\dot{Q}_{\mathrm{m}_{2}}=0.644 \dot{Q}_{\mathrm{m}}$. To mimic the injection of primary and secondary air, as done in some combustion chambers, $60 \%$ of the total mass of air is introduced at the initial time, the rest of air particles are then progressively released over $1 \mathrm{~ms}$. The third and last 
inlet of burnt gases, taken at chemical equilibrium for the equivalence ratio of the full mixture at $T=1877 \mathrm{~K}$, brings $\dot{Q}_{\mathrm{m}_{3}}=0.333 \dot{Q}_{\mathrm{m}}$. These $33 \%$ were estimated from large eddy simulation of a representative aeronautical combustion chamber 27] and these burnt gases secure ignition in a first set of calculations.

As in Farcy et al. 20], the elementary mass flow rate $\dot{q}_{m}=\dot{q}_{m_{\mathrm{L}}}^{p}(t)+$ $\dot{q}_{m_{\mathrm{G}}}^{p}(t)$ carried by every $p$-th particle $\left(p=1, \cdots, N_{\mathrm{P}}\right)$ is decomposed into liquid $\left(\dot{q}_{m_{\mathrm{L}}}^{p}(t)\right)$ and gas $\left(\dot{q}_{m_{\mathrm{G}}}^{p}(t)\right)$ phases. The evolution of the thermochemical property $\phi^{p}$ carried by the $p$-th stochastic particles reads

$$
\frac{d \phi^{p}(t)}{d t}=\operatorname{MIX}^{p}(\tau)+\dot{\omega}_{\phi}^{p}+\dot{\omega}_{\mathbf{v}_{\phi}}^{p},
$$

where $\dot{\omega}_{\phi}^{p}$ is the gaseous phase chemical source obtained from the chemical scheme, $\dot{\omega}_{\mathbf{v}_{\phi}}^{p}$ relates to the liquid fuel (evaporation or heat), computed from the particle properties. $\operatorname{MIX}^{p}(\tau)$ denotes the Curl 16 micro-mixing closure, with $\tau$ the characteristic micro-mixing time. Many other micro-mixing models exist in the literature, like modified Curl [18,26], Euclidian Minimum Spanning Tree (EMST) 64], Multiple Mapping Conditioning (MMC), which allows for introducing flamelet-like correlations between species [60], or again the advanced hierarchical parcel-swapping representation of turbulent mixing [33]. However, for examining the global scaling laws considered in this work, the basic version of the Curl micro-mixing model was found sufficient.

To account for the evaporation of the liquid fuel, the simplified modeling used in 20] is adopted. The thermal condition is assumed above the liquid boiling point and the droplets diameter follows the so-called $\mathrm{D}^{2}$-law $\left.55,56,59\right]$, $d_{j}^{2}(t)=d_{j}^{2}\left(t_{\mathrm{o}}\right)\left(1-\left(t / \tau_{\mathrm{v}}\right)\right)$. The characteristic evaporation time is fixed at $\tau_{\mathrm{v}}=$ $0.491 \mathrm{~ms}$, which was estimated from the experimental results by Nomura et al 44]. It was thus preferred to fix $\tau_{\mathrm{v}}$ from experiments, rather than introducing additional uncertainties in its dynamic calculation from approximate liquid and flow properties.

The rate of gaseous mass of the $i$-th component released by a single droplet reads

$$
\dot{W}_{i}^{p}(t)=Y_{i, \mathrm{~L}}^{p}(t) \times \rho_{\mathrm{L}} \frac{\pi}{6}\left[\frac{d_{j}{ }^{3}(t)-d_{j}{ }^{3}(t+\Delta t)}{\Delta t}\right],
$$

where $Y_{i, \mathrm{~L}}^{p}$ denotes the mass fraction of the $i$-species in the liquid of the $p$-th particle. A single stochastic particle issued from the $j$-th inlet carries a number $\dot{n}_{j}$ of droplets injected per unit time. Then, the balance between liquid and gaseous mass flow rates carried by a given particle issued from the $j$-th inlet may be written

$$
\begin{aligned}
& \dot{q}_{m_{\mathrm{G}}}^{p}(t+\Delta t)=\dot{q}_{m_{\mathrm{G}}}^{p}(t)+\sum_{i=1}^{N_{\mathrm{s}}} \dot{n}_{j} \dot{W}_{i}^{p}(t) \Delta t, \\
& \dot{q}_{m_{\mathrm{L}}}^{p}(t+\Delta t)=\dot{q}_{m_{\mathrm{L}}}^{p}(t)-\sum_{i=1}^{N_{\mathrm{s}}} \dot{n}_{j} \dot{W}_{i}^{p}(t) \Delta t,
\end{aligned}
$$


where $N_{\mathrm{s}}$ is the number of species considered. The net gaseous source of evaporation of the $i$-th chemical species in the $p$-th particle is

$$
\dot{\omega}_{\mathrm{v}_{i}}^{p}(t)=\frac{1}{\Delta t}\left[\frac{\dot{q}_{m_{\mathrm{G}}}^{p}(t) Y_{i, \mathrm{G}}^{p}(t)+\dot{n}_{j} \dot{W}_{i}^{p}(t) \Delta t}{\dot{q}_{m_{\mathrm{G}}}^{p}(t+\Delta t)}-Y_{i, \mathrm{G}}^{p}(t)\right]
$$

where $Y_{i, \mathrm{G}}^{p}$ is the gaseous mass fraction of the $i$-th species in the $p$-th particle. The source of the sensible enthalpy $h_{s}$ is

$$
\dot{\omega}_{\mathrm{v}_{h_{s}}}^{p}(t)=\frac{1}{\Delta t}\left[\frac{\dot{q}_{m_{\mathrm{G}}}^{p}(t) h_{s}^{p}(t)+\sum_{i=1}^{N} \dot{n}_{j} \dot{W}_{i}^{p}(t)\left[h_{i}\left(T_{B}\right)-\mathcal{L}_{v_{i}}\right] \Delta t}{\dot{q}_{m_{\mathrm{G}}}^{p}(t+\Delta t)}-h_{s}^{p}(t)\right]
$$

in which $T_{B}=750 \mathrm{~K}$ is the boiling temperature, $h_{i}$ is the enthalpy of the $i$-th species and $\mathcal{L}_{v_{i}}=251000 \mathrm{~J} / \mathrm{kg}$ is the latent heat of evaporation. At injection, a single droplet diameter $d=12.8 \mu \mathrm{m}$ is imposed, as it was estimated from the Sauter mean diameter of a representative aeronautical injector. This modeling leads to usual and generic scatter plot responses, as seen in Fig. 3.

\begin{tabular}{llr}
\hline Transported species & $\begin{array}{l}\text { Analytically resolved species } \\
(\mathbf{Q S S})\end{array}$ \\
\hline $\mathrm{H}_{2}, \mathrm{O}_{2}, \mathrm{CO}, \mathrm{CO}_{2}, \mathrm{CH}_{4}, \mathrm{C}_{2} \mathrm{H}_{6}, \mathrm{CH}_{2} \mathrm{O}$, & $\mathrm{HCO}, \mathrm{CH}_{3} \mathrm{OH}, \mathrm{C}_{2} \mathrm{H}_{5}, \mathrm{CH}_{3} \mathrm{O}, \mathrm{CH}_{2} \mathrm{OH}$, \\
$\mathrm{C}_{2} \mathrm{H}_{2}, \mathrm{C}_{2} \mathrm{H}_{4}, \mathrm{C}_{3} \mathrm{H}_{6}, \mathrm{C}_{4} \mathrm{H}_{6}, \mathrm{NC}_{10} \mathrm{H}_{22}$, & $\mathrm{CH}_{2} \mathrm{CO}, \mathrm{C}_{2} \mathrm{H}_{3}, \mathrm{CH}_{2} \mathrm{HCO}, \mathrm{HCCO}$, \\
$\mathrm{H}, \mathrm{O}, \mathrm{OH}, \mathrm{HO}_{2}, \mathrm{H}_{2} \mathrm{O}, \mathrm{CH}_{3}, \mathrm{C}_{3} \mathrm{H}_{3}$, & $\mathrm{NC}_{3} \mathrm{H}_{7}, \mathrm{PC}_{4} \mathrm{H}_{9}, \mathrm{AC}_{6} \mathrm{H}_{13}, \mathrm{AC}_{8} \mathrm{H}_{17}$, \\
$\mathrm{AC}_{3} \mathrm{H}_{5}, \mathrm{BC}_{6} \mathrm{H}_{13}, \mathrm{~N}_{2}$ & $\mathrm{C}_{10} \mathrm{H}_{21}(\mathrm{~L})$ \\
$\mathrm{NO}, \mathrm{HCN}, \mathrm{N}_{2} \mathrm{O}, \mathrm{NO}_{2}$ & $\mathrm{HNO}, \mathrm{HONO}, \mathrm{H}_{2} \mathrm{CN}, \mathrm{NNH}, \mathrm{NH}_{2}, \mathrm{NH}$, \\
& $\mathrm{N}, \mathrm{CN}, \mathrm{NCO}, \mathrm{HNCO}$ \\
\hline
\end{tabular}

Table 1 Species of a n-decane $\left(\mathrm{n}-\mathrm{C}_{10} \mathrm{H}_{22}\right)$ reduced mechanism composed of 26 transported species associated to 24 QSS relations and 338 reactions.

\section{Reduced n-decane chemistry}

The Luche et al. 40, 41] chemical kinetics accounts for 91 species and 991 reacting steps, and is derived from the more detailed kerosene-air mechanism by Dagaut [17]. This mechanism was selected because of its reasonable size, at least in comparison to other more detailed schemes for kerosene-air combustion. It is not attempted to provide in this work a reduced chemistry for kerosene that would benefit from the most recent findings in terms of real aeronautical fuels 62], which may include complex chemical properties distributions across the distillation curve and related complex phenomena. The sole objective is to compare the normalised response of a chemical scheme featuring multiple chemical time scales against the scaling laws discussed thereafter, and using the Luche et al. mechanism as a starting point is sufficient to address this point. 

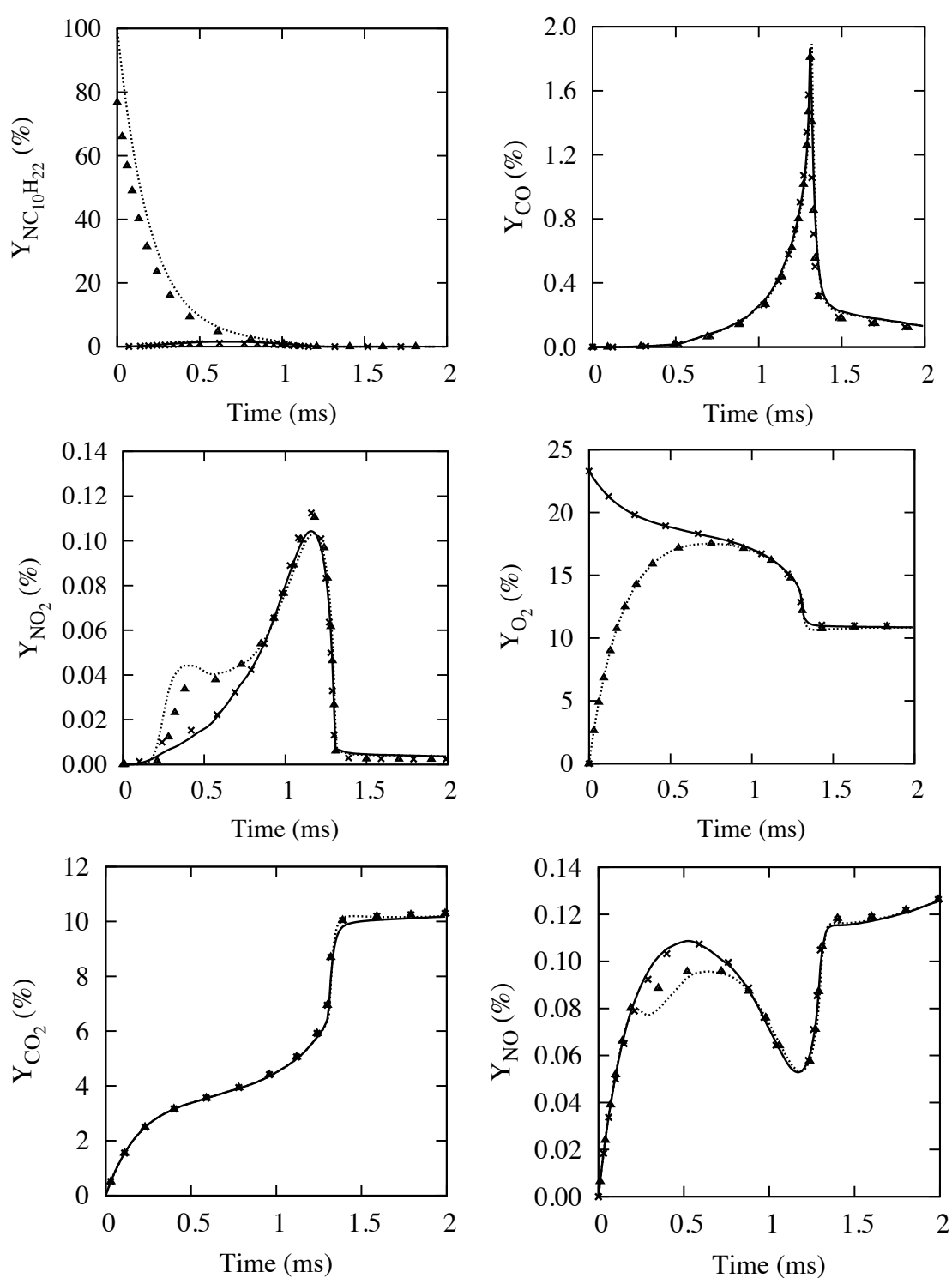

Fig. 4 Representative species trajectories (Eq. 9 ) for the kerosene surrogate and n-decane reduced mechanism. $\tau=0.2$ ms. Symbols: Reference chemistry 41]. Lines: Reduced n-decane mechanism (Table 1). Solid-line: Air inlet trajectory. Dotted-Line: Fuel inlet trajectory.

To further reduce the Luche et al. chemistry so that multiple calculations can be performed, the ORCh approach is followed 29], which combines the directed graph analysis with error propagation (DRGEP) 39, 45. Species and reactions are progressively removed according to their relative importance measured along reference chemical evolutions $\left(\phi^{\mathrm{D}}(t)\right.$ trajectories $)$, with the 
automatic generation of an analytical part using quasi-steady state assumption (QSS) and a subsequent optimisation of the chemical rates with a Genetic Algorithm. All detail concerning this combination of reduction/optimisation methods to generate a series of reduced chemical kinetics can be found in 28 , 29 .

To compact the information and ease the analysis, two additional deterministic trajectories are solved, from the air and kerosene inlets, with the linear relaxation deterministic micro-mixing closure (IEM or LMSE) 7,19

$$
\frac{d \phi^{\mathrm{D}}(t)}{d t}=\frac{\langle\phi\rangle(t)-\phi^{\mathrm{D}}(t)}{\tau}+\dot{\omega}_{\phi}^{\mathrm{D}} .
$$

The statistical mean entering this deterministic mixing model is computed at every instant in time from the full set of stochastic particles,

$$
\langle\phi\rangle(t)=\frac{\sum_{p=1}^{N_{\mathrm{P}}} \dot{q}_{m_{G}}^{p}(t) \phi^{p}(t)}{\sum_{p=1}^{N_{P}} \dot{q}_{m_{\mathrm{G}}}^{p}(t)} .
$$

These additional deterministic trajectories are easily coupled with a Genetic Algorithm, to optimise chemical rates after chemistry reduction 29]. Figure 4 shows typical $\phi^{\mathrm{D}}(t)$ distributions.

The kerosene in the initial mechanism by Luche et al. 40, 41] is a surrogate composed of n-decane $\left(\mathrm{n}-\mathrm{C}_{10} \mathrm{H}_{22}, 76.7388 \%\right.$ in mass), propylbenzene $\left(\mathrm{PHC}_{3} \mathrm{H}_{7}, 13.1402 \%\right)$ and propylcyclohexane $\left(\mathrm{CYC}_{9} \mathrm{H}_{18}, 10.1210 \%\right)$. In the present reduction, the initial composition of the fuel is even more simplified to $100 \%$ n-decane. The species of the reduced mechanism are given in Table 1 . This mechanism relies on the transport of 26 chemical species and on the solving of 24 quasi-steady state relations and contains 338 elementary reactions.

The associated trajectories (Eq. (9)) for operating conditions reported above are displayed in Figs. 4 and 5 , in which the symbols denote the detailed scheme. The trajectories from fuel and air inlet differ till a residence time of $1 \mathrm{~ms}$, before the species evolve toward the equilibrium condition. The thermal energy brought by the burnt gases first promote the formation of NO through their mixing with fresh air. At $0.5 \mathrm{~ms}$, the temperature conditions are so that part of this $\mathrm{NO}$ is recombined into $\mathrm{NO}_{2}$, to then increase again after $1.25 \mathrm{~ms}$ through the mixing with the remaining air in a post-flame region. Aside from the unavoidable difference in n-decane (fuel surrogate in the detailed mechanism and only n-decane in the reduced one in Fig. 3), the response of the reduced scheme stays very close to the detailed one, specifically in terms of position of ignition and of the peak of CO (Fig. 3), which will be considered thereafter in the analysis increasing $\mathrm{Ka}$ and varying the amount of burnt gases.

The reduced mechanism has been obtained considering only the turbulent micro-mixing problem (Eq. 3), which overall features similarities with non-premixed combustion. It is therefore of interest to verify that a perfectly premixed combustion regime is also reproduced. Figure 6 shows a comparison 


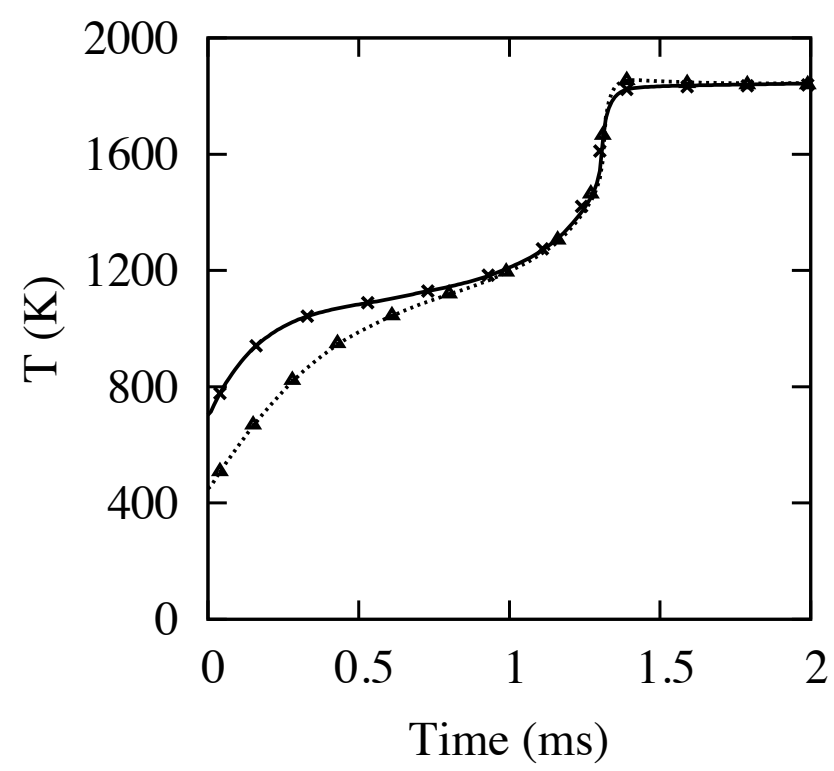

Fig. 5 Temperature trajectories (Eq. 99 ). $\tau_{\mathrm{T}}=0.2 \mathrm{~ms}$. Symbols: Reference chemistry 41 . Lines: Reduced n-decane mechanism (Table 11. Solid-line: Air inlet trajectory. Dottedline: Fuel inlet trajectory.

of the flame velocity, the equilibrium temperature and the equilibrium levels for $\mathrm{CO}$ and for $\mathrm{NO}$ obtained from perfectly premixed kerosene-air flame computations at a pressure of $9.63 \cdot 10^{5} \mathrm{~Pa}$ with the Cantera solver 22. Some departure is observed on the estimation of the flame speed $S_{\mathrm{L}}$ for equivalence ratios between unity and 2 , but overall the description is acceptable considering the level of reduction. For comparison, are added the results obtained with a less reduced chemical mechanism (32 transported species, with 27 QSS relations and 419 elementary reactions), obtained keeping the original surrogate fuel composition. Both reduced mechanisms perfectly capture the equilibrium temperature and equilibrium $\mathrm{CO}$ level for every equivalence ratio. An over prediction of the NO levels is achieved using the most reduced mechanisms for conditions around the stoichiometric point. However, because NOx species will not be considered in the subsequent analysis, this most reduced mechanism based on n-decane (Table 1) is retained.

\section{Basic scaling for high-Ka flames in vitiated mixture}

Oversimplified scaling relations for weakly vitiated flames are recalled in this section. 


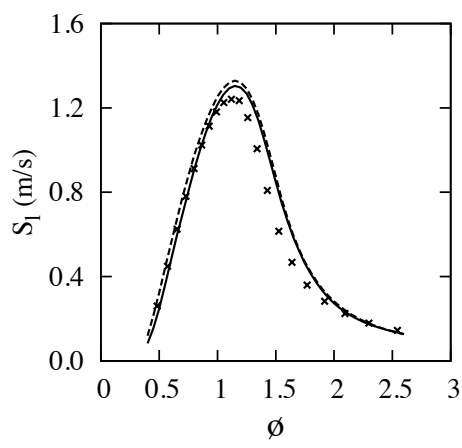

(a) Flame speed

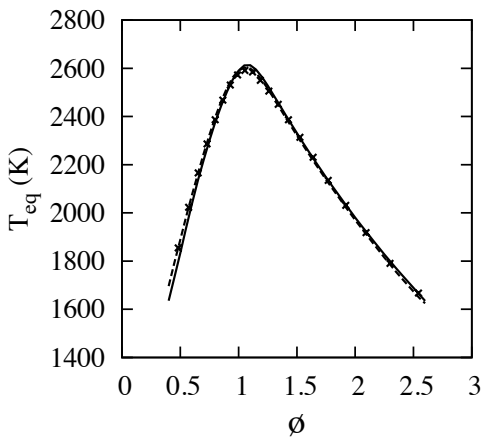

(c) Temperature

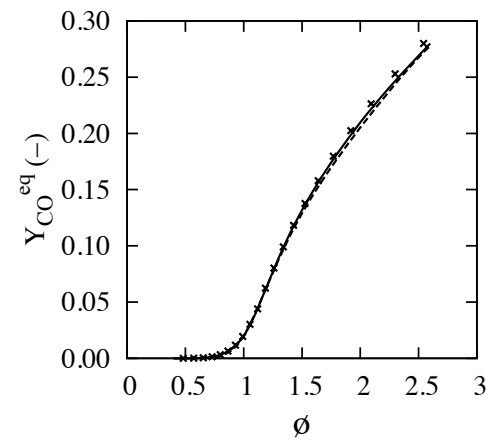

(b) $\mathrm{CO}$ mass fraction

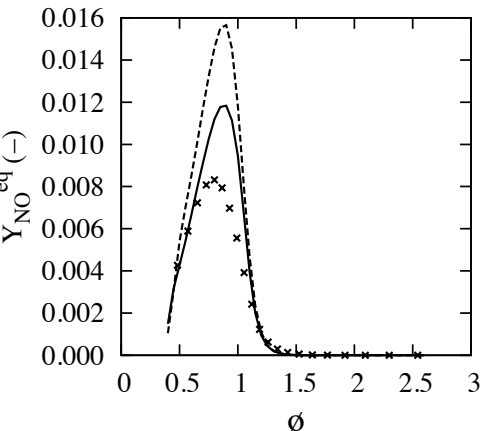

(d) NO mass fraction

Fig. 6 Freely propagating premixed flames. Response versus equivalence ratio, species and temperature taken in burnt gases. Symbols: Reference chemistry 41]. Solid-line: Reduced surrogate mechanism. Dashed-line: Reduced n-decane mechanism (Table 1.

4.1 Vitiated steady premixed flamelet

Consider the steady premixed laminar flamelet equation

$$
\rho u \frac{d \phi}{d \xi}=\frac{d}{d \xi}\left(\rho D_{\phi} \frac{d \phi}{d \xi}\right)+\dot{\omega}_{\phi}-\rho \dot{S}_{\mathrm{K}_{\phi}},
$$

where $\rho$ is the density, $u$ is the velocity, $D_{\phi}$ is the diffusion coefficient of the scalar $\phi$ evolving through the flame front and $\dot{\omega}_{\phi}$ its chemical source. The coordinate in the direction normal to the flame front is $\xi$ and $\dot{S}_{\mathrm{K}_{\phi}}$ is a leakage term, representative of all fluxes occurring along the flame surface [21], as transverse convection and diffusion resulting from straining and curvature of the flamelet surface.

The fresh gases condition $\phi_{\mathrm{u}}$ is expressed from a reference fresh gases unburnt condition $\phi_{\mathrm{o}}$ and the dilution (or vitiation) factor $f_{\mathrm{b}}$ (the subscript ' $\mathrm{u}$ ' and ' $b$ ' denote unburnt and burnt gases respectively)

$$
\phi_{\mathrm{u}}=\phi_{\mathrm{o}}\left(1-f_{\mathrm{b}}\right)+f_{\mathrm{b}} \phi_{\mathrm{b}} .
$$


$f_{\mathrm{b}}=0$ corresponds to fresh mixtures (fuel mixed with oxidiser) and burnt vitiated gases appears for $0<f_{\mathrm{b}}<<1$.

Integrating (11) through an unstrained one-dimensional flame $\left(\dot{S}_{\mathrm{K}_{\phi}}=0\right)$ and accounting for mass conservation, the unstrained flame speed reads

$$
S_{\mathrm{L}}\left(f_{\mathrm{b}}, \dot{S}_{\mathrm{K}_{\phi}}=0\right)=u_{\mathrm{u}}=\left(\frac{\rho_{\mathrm{b}}}{\rho_{\mathrm{u}}}\right) u_{\mathrm{b}}=\frac{1}{\phi_{\mathrm{b}}-\phi_{\mathrm{u}}}\left[\frac{1}{\rho_{\mathrm{u}}} \int_{-\infty}^{+\infty} \rho \dot{\omega}_{\phi} d \xi\right] .
$$

The peak reaction rate in the integral in Eq. 13 is toward the burnt gaz side, also it is assumed that the density weighted integral of the source does not vary much with dilution by burnt gases, at least for weak levels of $f_{\mathrm{b}}$. Combining this hypothesis with the relations $(13)$ and $(12)$ leads to

$$
\begin{aligned}
S_{\mathrm{L}}\left(f_{\mathrm{b}}, \dot{S}_{\mathrm{K}_{\phi}}=0\right) & =\frac{1}{1-f_{\mathrm{b}}} \times \frac{1}{\phi_{\mathrm{b}}-\phi_{\mathrm{o}}}\left[\frac{1}{\rho_{\mathrm{o}}} \int_{-\infty}^{+\infty} \rho \dot{\omega}_{\phi} d \xi\right] \\
& =\left(\frac{1}{1-f_{\mathrm{b}}}\right) S_{\mathrm{L}}^{\mathrm{o}}
\end{aligned}
$$

with $S_{\mathrm{L}}^{\mathrm{o}}=S_{L}\left(f_{\mathrm{b}}=0, \dot{S}_{\mathrm{K}_{\phi}}=0\right)$. Figure 7 shows the evaluation of this relation in the simulation of a freely propagating premixed flame with a single-step chemistry cast as in 38, for a Zeldovitch number $\beta=15$. The expected trend is recovered for $0<f_{\mathrm{b}}<<1$. In this single-step chemistry simulation, the addition of the vitiated gases is mimicked by preheating the fresh mixture, and the one-dimensional flame is computed with a fully compressible sixthorder flow solver using a PADE scheme 36 . This hyperbolic behaviour of flame speed versus dilution by burnt gases was also reported in the literature at various places, for instance simulating vitiated premixed flamelets with detailed chemistry (see Fig. 4a in 63]) ${ }^{1}$

Considering now a flamelet submitted to stretch without dilution and assuming that the integral of the source stays close to the unstretched flame burning velocity, Eq. (11) leads to

$$
\begin{aligned}
\rho_{\mathrm{o}} S_{\mathrm{L}}\left(f_{\mathrm{b}}=0, \dot{S}_{\mathrm{K}_{\phi}}\right) & =\frac{1}{\phi_{\mathrm{b}}-\phi_{\mathrm{o}}}\left[\int_{-\infty}^{+\infty} \rho \dot{\omega}_{\phi} d \xi-\int_{-\infty}^{+\infty} \rho \dot{S}_{\mathrm{K}_{\phi}} d \xi\right] \\
& =\rho_{\mathrm{o}} S_{\mathrm{L}}^{\mathrm{o}}\left(1-\frac{-\infty}{\left(\phi_{\mathrm{b}}-\phi_{\mathrm{o}}\right) \rho_{o} S_{\mathrm{L}}^{\mathrm{o}}}\right) .
\end{aligned}
$$

The usual linear response of the flame speed to small levels of stretch is found 15

$$
S_{\mathrm{L}}\left(f_{\mathrm{b}}=0, \dot{S}_{\mathrm{K}_{\phi}}\right)=S_{\mathrm{L}}^{\mathrm{o}}(1-\mathrm{K}),
$$

1 This scaling may also be retrieved from high-activation energy asymptotic developments after matching fluxes with vitiated fresh gases 8. 


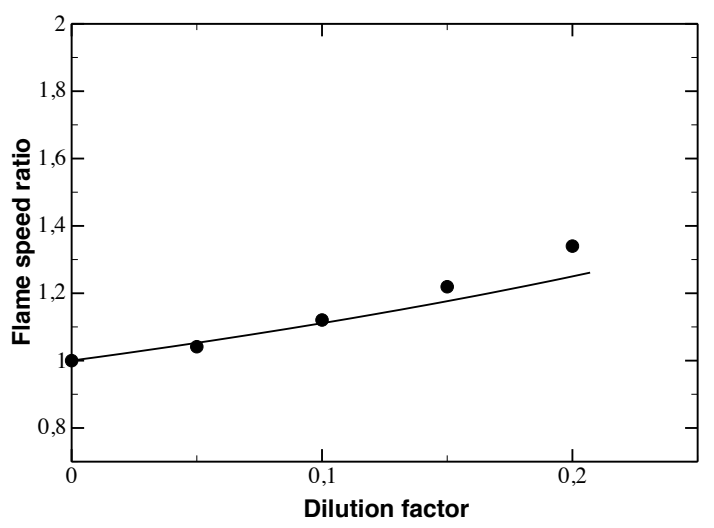

Fig. 7 Flame speed $S_{L}\left(f_{\mathrm{b}}\right)$ versus the dilution factor $f_{\mathrm{b}} 12$. Line: Eq. 14 Symbol: Simulation of $1 \mathrm{D}$ freely propagating premixed flame.

with $\left(\phi_{\mathrm{b}}-\phi_{\mathrm{o}}\right) \rho_{o} S_{\mathrm{L}}^{\mathrm{o}} \times \mathrm{K}=\int_{-\infty}^{+\infty} \rho \dot{S}_{\mathrm{K}_{\phi}} d \xi$.

The linear reduction of flame speed by $(1-\mathrm{K})(\mathrm{Eq} .116 \mathrm{)})$ and the increase of flame speed by $\left(1-f_{\mathrm{b}}\right)^{-1}$ (Eq. (14)), suggest that the effect of flame speed reduction by tangential stretch applied to the flame surface can be compensated by the vitiation of the fresh gases.

\subsection{Vitiated diffusion flamelet quenching}

The relation (14) for the unstretched and diluted flame may also be combined with an estimation of the quenching condition in a diffusion flamelet. $\tau_{\mathrm{m}_{\mathrm{q}}}$ the mechanical time at quenching in a non-premixed system is known to relate to the stoichiometric and freely propagating flame speed as 46,47

$$
\frac{1}{\tau_{\mathrm{m}_{\mathrm{q}}}}=\frac{Z_{\mathrm{st}}^{2}\left(1-Z_{\mathrm{st}}\right)^{2}}{a_{T} / S_{L}^{2}}
$$

where $a_{T}$ is the thermal diffusivity and $Z_{\text {st }}$ the stoichiometric value of the mixture fraction 47. Assuming a fixed reference chemical time, $\mathrm{Ka}_{\mathrm{q}}$, the Karlovitz number at quenching varies as $\tau_{\mathrm{m}_{\mathrm{q}}}^{-1}$. The introduction in 17p of the relation 144, giving the unstrained flame speed $S_{\mathrm{L}}=S_{\mathrm{L}}\left(f_{\mathrm{b}}, \dot{S}_{\mathrm{K}}=0\right)$ in the presence of dilution, provides a scaling relation for a non-premixed system weakly vitiated by burnt gases

$$
\operatorname{Ka}_{\mathrm{q}}\left(f_{\mathrm{b}}\right) \approx\left(\frac{1}{1-f_{\mathrm{b}}}\right)^{2} .
$$

Hence, the value of the Karlovitz number at the quenching point should increase in the presence of dilution by burnt gases $\left(f_{\mathrm{b}}>0\right)$, making the reaction zones evolving in vitiated mixture more robust to intense turbulence. This scaling is now tested against calculations with the reduced kerosene chemistry. 


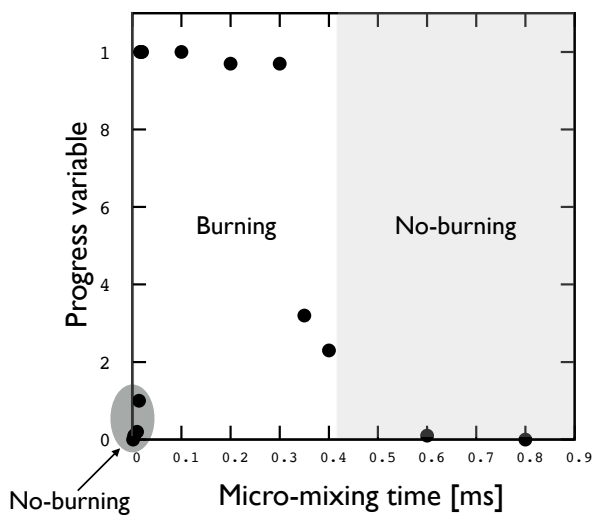

(a) Full range

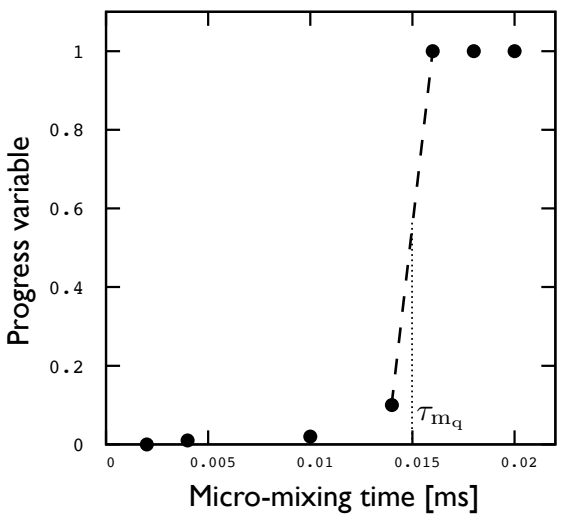

(b) High Ka zone

Fig. 8 Response of the progress variable $c^{\mathrm{D}}\left(t_{\text {End }}\right)$ versus mechanical mixing time. $f_{\mathrm{b}}=0.5$ and $t_{\text {End }}=2 \mathrm{~ms}$.

\section{Response of $\mathrm{Ka}$ at quenching in a vitiated stream}

The above dilution factor $f_{\mathrm{b}}$ calibrates the relative amount of burnt and fresh gases present in the unburnt mixture (Eq. (12)). In the canonical problem used for chemistry reduction (Eqs. (3) and (9p), the relative amount of burnt gases introduced initially may be varied adjusting the mass flow rates of the three streams injected in the system $\left(\dot{Q}_{\mathrm{m}_{1}}\right.$ : fuel, $\dot{Q}_{\mathrm{m}_{2}}$ : air and $\dot{Q}_{\mathrm{m}_{3}}$ : burnt gases), thus varying $\left\langle Y_{i}(t=0)\right\rangle$, the averaged mass fractions injected at $t=0$, including liquid fuel.

To study the sensitivity of the pseudo-reactor to the amount of added recirculating burnt gases, $f_{\mathrm{b}}$ is defined as

$$
f_{\mathrm{b}}=\frac{\dot{Q}_{\mathrm{m}_{3}}}{\dot{Q}_{\mathrm{m}}-\dot{Q}_{\mathrm{m}_{3}}} .
$$

where $\dot{Q}_{\mathrm{m}}=\sum_{j} \dot{Q}_{\mathrm{m}_{j}}$ is the total mass flow rate injected. With this definition, $f_{\mathrm{b}}=0$ in the case of no-dilution by burnt gases and $f_{\mathrm{b}}=1$ in the asymptotic limit where mass flow rates of fresh $\left(\dot{Q}_{\mathrm{m}_{1}}+\dot{Q}_{\mathrm{m}_{2}}\right)$ and burnt gases $\left(\dot{Q}_{\mathrm{m}_{3}}\right)$ are equal.

The response of the turbulence/chemistry interaction to variations of $\tau$, the micro-mixing time, is characterized by three stages $[38$. (i) very small micromixing times, and thus very fast micro-mixing, prevent combustion. (ii) intermediate values of $\tau$ lead to ignition and burning with turbulence/chemistry interaction. (iii) above a given threshold, the too large micro-mixing times, associated with very small frequency of micro-mixing, do not allow for sufficient mixing of the fresh and burnt gases to secure ignition within the allowed residence time (here $2 \mathrm{~ms}$ ). These three stages ((i) no-burning, (ii) burning and (iii) no-burning) are seen in Fig. 8, displaying $\langle c\rangle$, the average progress variable ( $c=0$ in the fresh gases and $c=1$ in fully burnt products) plotted 


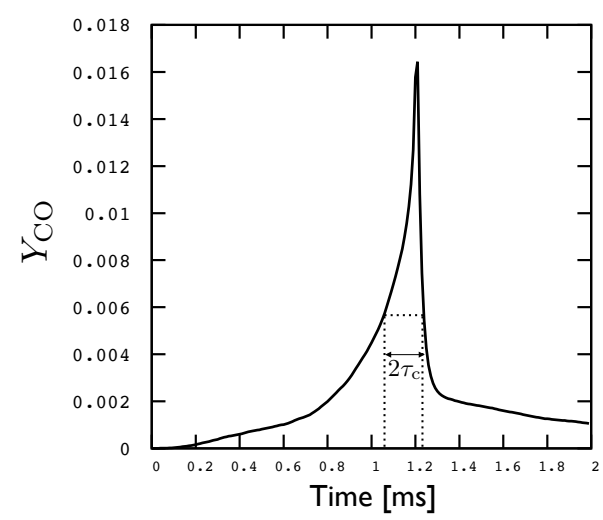

Fig. 9 Illustration of the arbitrary definition of the chemical time from $Y_{\mathrm{CO}}^{\mathrm{D}}(t)$, the $\mathrm{CO}$ mass fraction deterministic trajectory (Eq. 97 ). Representative case $f_{\mathrm{b}}=0.5$.

at $t_{\text {End }}=2 \mathrm{~ms}$ for cases featuring a micro-mixing time $\tau$ varying between $0.002 \mathrm{~ms}$ and $0.8 \mathrm{~ms}$, and for the representative case $f_{\mathrm{b}}=0.5$. The average progress of reaction $\langle c\rangle$ is here calculated from the normalised production of $\mathrm{CO}_{2}$ by combustion

$$
\langle c\rangle(t)=\frac{\left\langle Y_{\mathrm{CO}_{2}}\right\rangle(t)-\left\langle Y_{\mathrm{CO}_{2}}\right\rangle(t=0)}{Y_{\mathrm{CO}_{2}}^{\mathrm{Eq}^{\star}}-\left\langle Y_{\mathrm{CO}_{2}}\right\rangle(t=0)},
$$

with $Y_{\mathrm{CO}_{2}}^{\mathrm{Eq}^{\star}}$ calculated from the full mixture at $t=0$, including primary and secondary air.

A zoom in the high-Ka zone is given in Fig. 8(b). The decrease of $\tau$ down to $\tau=0.015 \mathrm{~ms}$ (thus the increase of $\mathrm{Ka}$ ) is followed by a rapid transition from burning to non-burning in the progress variable response. The mid-point of a linear distribution constructed between the last fully burning point and the first very weakly burning condition is chosen to define, $\tau_{\mathrm{m}_{\mathrm{q}}}$, the mechanical time at quenching. This determines the smallest micro-mixing time that does allow for ignition and burning in the combustion problem defined by Eq (3). The corresponding quenching Karlovitz number can then be related to a limit value that would prevent ignition and thus flame stabilisation in burnt gases vitiated mixture.

The dilution factor $f_{\mathrm{b}}$ (Eq. 190$)$ is now varied between 0.25 and 1. For every case, a set of trajectories (Eq. (9) ) are obtained for given values of $\tau$, to determine the response of $\tau_{\mathrm{m}_{\mathrm{q}}}$ versus $f_{\mathrm{b}}$, according to the procedure shown in Fig. 8(b), To define a Karlovitz number, a chemical time must be chosen. With complex chemistry, in the present case 48 species, many options exist. After considering the evolution of various species, the trajectories of carbon monoxyde were found to provide a similar shape for the various dilution levels, it is also a species which is well captured by the reduced scheme (Fig. 3). The decay of the $\mathrm{CO}$ mass fraction after its peak value can be interpolated

$$
Y_{\mathrm{CO}}(t)=Y_{\mathrm{CO}}^{\max } \exp \left(-\left(t-t_{\text {peak }}\right) / t_{\mathrm{o}}\right)
$$




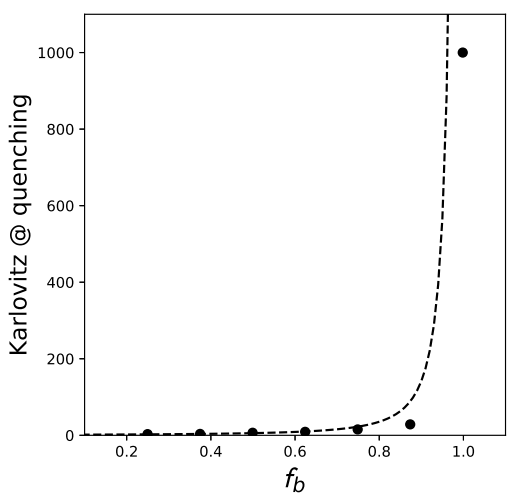

(a) Full range

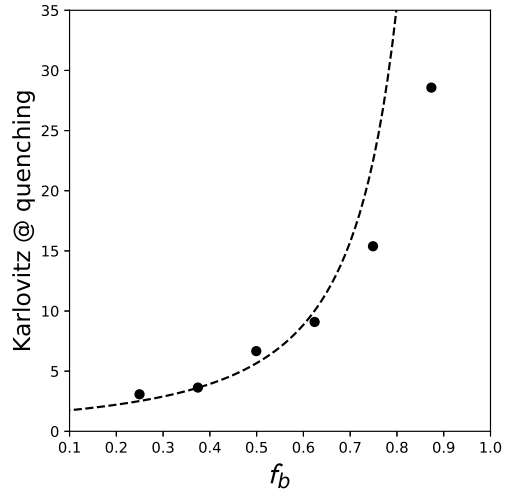

(b) Zoom for lower values

Fig. 10 Response of $\mathrm{Ka}_{\mathrm{q}}$ versus $f_{\mathrm{b}}$. Circle: simulations (Eqs. 3 and 9 ). Dashed line: Eq. 18 (b): zoom in moderate Ka level.

where $Y_{\mathrm{CO}}^{\max }=Y_{\mathrm{CO}}\left(t_{\text {peak }}\right)$ denotes the peak $\mathrm{CO}$ mass fraction (Fig. 9). The characteristic relaxation time $t_{\mathrm{o}}$ is measured from the observed $\mathrm{CO}$ distribution, so that $Y_{\mathrm{CO}}\left(t_{\text {peak }}+t_{\mathrm{o}}\right)=Y_{\mathrm{CO}}^{\max } \exp (-1)$. Twice the chemical time, $2 \tau_{\mathrm{c}}$, is arbitrarily chosen as the time duration between the two observations of $Y_{\mathrm{CO}}^{\max } \exp (-1)$ in the $\mathrm{CO}$ distributions (Fig. 9). The value of the Karlovitz at quenching for various $f_{\mathrm{b}}$ is finally taken as the ratio

$$
\operatorname{Ka}_{\mathrm{q}}\left(f_{\mathrm{b}}\right)=\frac{\tau_{\mathrm{c}}}{\tau_{\mathrm{m}_{\mathrm{q}}}} .
$$

Obviously, other formulations could be introduced, however this global measure is sufficient to compare against the basic scaling discussed above.

The response of $\mathrm{Ka}_{\mathrm{q}}$ versus the dilution factor $f_{\mathrm{b}}$ is given in Fig. 10. The robustness of the $n$-decane combustion to intense mixing does increase with dilution by burnt gases. A rapid growth of the value of $\mathrm{Ka}_{\mathrm{q}}$ at quenching is particularly observed after reaching $f_{\mathrm{b}}=0.6$ (Fig. $10(\mathrm{~b})$. Interestingly, a zoom in the lower values of $f_{\mathrm{b}}$ shows that the response of $\mathrm{Ka}_{\mathrm{q}}$ follows quite well the scaling given by Eq. (18). It is worthwhile to note that the relation (18), which was derived for $0<f_{\mathrm{b}}<<1$ (thus without matching in the onedimensional approximate analysis the $f_{\mathrm{b}}$ definition based on the mass flow rate (19)), seems here reasonably fit for approximating the flame response, even up to large values of $f_{\mathrm{b}}$.

\section{Discussion and summary}

A stochastic canonical problem has been constructed to explore turbulence chemistry/interaction with kerosene liquid fuel injection. The information obtained has been used at first to optimise a reduced chemical scheme, whose 
objective is to predict major species only. Then, the response of the quenching Karlovitz number to the amount of burnt gases mixed with the fresh mixture has been studied. It is found that basic scaling laws derived for burnt-gases vitiated premixed and non-premixed systems agree well with the results, with dilution promoting an inverse squared enhancement of the flame robustness to intense turbulence.

Estimating characteristic length and time scales relevant for turbulent flames in real combustion systems, or in experiments representative of real injectors, is not an easy task 30]. Along these lines, well-resolved Large Eddy Simulation (LES) or quasi Direct Numerical Simulation (DNS) of real burners provide additional information. The Table 6 summarises length and time scales extracted from the quasi-DNS [43] of the aeronautical swirl burned studied experimentally by Meier et al. 42 .

\begin{tabular}{|c|c|c|c|c|c|}
\hline $\mathrm{Re}_{\mathrm{T}}$ & $\mathrm{Re}_{\lambda}$ & $\ell_{\mathrm{T}}$ & $\tau_{\mathrm{T}}$ & $\eta_{\mathrm{k}}$ & $\tau_{\mathrm{k}}$ \\
\hline 1480 & 149 & $7 \mathrm{~mm}$ & $2 \mathrm{~ms}$ & $29 \mu \mathrm{m}$ & $0.051 \mathrm{~ms}$ \\
\hline
\end{tabular}

Table 2 Characteristic length scales approximated from quasi-DNS of a swirl burner 42 43].

In Fig. 8 for $f_{\mathrm{b}}=0.5$, combustion is expected for micro-mixing times in the range $0.015 \mathrm{~ms}<\tau<0.1 \mathrm{~ms}$. Interestingly, $\tau_{\mathrm{k}}$ in Table 6 lies within this range, close to the lower limit for this swirled flow injector, which was designed to operate with a quite strong precessing vortex core, featuring a characteristic frequency of about $540 \mathrm{~Hz}$ with a time scale of the order of $1.9 \mathrm{~ms}$, thus with strong recirculation of burnt gases. Drawing further conclusions on the exact numbers would not be fair at this stage. However, above results open perspectives for advanced injector design, thus considering high Karlovitz combustion aside from toy problems. The opportunity of counterbalancing the negative impact of strong turbulence on the flame-base thanks to entrainment of burnt gases, appears actually stronger than expected from usual combustion regime analysis. At the same times, it confirms that high Karlovitz combustion can hardly be sustained without addition of burnt gases.

Acknowledgements The first author is supported by the European Union under the project SOPRANO, Horizon 2020 Grant Agreement No. 690724. The second author was funded by ANRT (Agence Nationale de la Recherche et de la Technology), SAFRAN-SNECMA and Air Liquide under the CIFRE No 1053/2013. Computing time has been provided by CRIANN (Centre Régional Informatique et d'Applications Numériques de Normandie).

\section{Compliance with Ethical Standards}

Conflict of Interest The authors declare that they have no conflict of interest. 


\section{References}

1. Aspden, A.J., Day, M.S., Bell, J.B.: Turbulence-chemistry interaction in lean premixed hydrogen combustion. Proc. Combust. Inst. 35(2), 1321-1329 (2015)

2. Aspden, A.J., Day, M.S., Bell, J.B.: Three-dimensional direct numerical simulation of turbulent lean premixed methane combustion with detailed kinetics. Combust. Flame 166, 266-283 (2016)

3. Bagdanavicius, A., Bowen, P.J., Bradley, D., Lawes, M., Mansour, M.S.: Stretch rate effects and flame surface densities in premixed turbulent combustion up to $1.25 \mathrm{MPa}$. Combust. Flame 162(11), 4158-4166 (2015)

4. Bédat, B., Cheng, R.K.: Experimental study of premixed flames in intense isotropic turbulence. Combust. Flame 100(3), 485-494 (1995)

5. Bobbitt, B., Blanquart, G.: Vorticity isotropy in high Karlovitz number premixed flames. Phys. Fluids 28, 1070- (2016)

6. Borghi, R.: Mise au point sur la structure des flammes turbulentes. J. Chimie Physique 81(6), 361-370 (1984)

7. Borghi, R.: Turbulent combustion modelling. Prog. Energy Combust. Sci. 14, 245-292 (1988)

8. Boulanger, J.: Asymptotic analysis and direct numerical simulation of partially premixed combustion. Ph.D. thesis, INSA de Rouen Normandie (2002)

9. Bradley, D., Lawes, M., Liu, K., Mansour, M.S.: Measurements and correlations of turbulent burning velocities over wide ranges of fuels and elevated pressures. Combust. Flame 34(1), 1519-1526 (2013)

10. Bray, K.N.C.: The challenge of turbulent combustion. Symp. (Int.) on Combust. 26 $1-26$ (1996)

11. Carlsson, H., Yu, R., Bai, X.S.: Direct numerical simulation of lean premixed CH4/air and H2/air flames at high Karlovitz numbers. Int. J. Hydrogen Energy 39(35), 20,216 $20,232(2014)$

12. Carlsson, H., Yu, R., Bai, X.S.: Flame structure analysis for categorization of lean premixed CH4/air and H2/air flames at high Karlovitz numbers: Direct numerical simulation studies. Proc. Combust. Inst. 35(2), 1425-1432 (2015)

13. Chomiak, J., Jarosinski, J.: Flame quenching by turbulence. Combust. Flame 48, 241$249(1982)$

14. Cicoria, D., Chan, C.K.: Large eddy simulation of lean turbulent hydrogen-enriched methane-air premixed flames at high Karlovitz numbers. Int. J. Hydrogen Energy 41(47), 22,479-22,496 (2016)

15. Clavin, P.: Premixed combustion and gasdynamics. Annu. Rev. Fluid Mech. 26, 321-52 (1994)

16. Curl, R.I.: Dispersed phase mixing. Theory and effects in simple reactors. AIChE $\mathbf{9}(2)$ 175-181 (1963)

17. Dagaut, P.: On the kinetics of hydrocarbons oxidation from natural gas to kerosene and diesel fuel. Physical Chemistry Chemical Physics 4(11), 2079-2094 (2002)

18. Dopazo, C.: Relaxation of initial probability density functions in the turbulent convection of scalar fields. Phys. Fluids 22(1), 20-30 (1979)

19. Dopazo, C., O'Brien, E.: Functional formulation of nonisothermal turbulent reactive flows. Phys. Fluids 17, 1968-1975 (1974)

20. Farcy, B., Vervisch, L., Domingo, P., Perret, N.: Reduced-order modeling for the control of selective non-catalytic reduction (SNCR). AIChE Journal 62(3), 928-938 (2016)

21. de Goey, L., Boonkkamp, J.T.T.: A flamelet description of premixed laminar flames and the relation with flame stretch. Combust. Flame 119, 253-271 (1999)

22. Goodwin, D.: Cantera: An object-oriented software toolkit for chemical kinetics, thermodynamics, and transport processes. http://code.google.com/p/cantera (2009)

23. Haiou, W., Hawkes, R., Chen, J.H.: A direct numerical simulation study of flame structure and stabilisation of an experimental high Ka CH4/air premixed jet flame. Combust. Flame 180, 110-123 (2017)

24. Han, I., Huh, K.Y.: Effects of the Karlovitz number on the evolution of the flame surface density in turbulent premixed flames. Proc. Combust. Inst. 32(1), 1419-1425 (2009) 
25. Huang, C.C., Shy, S.S., Liu, C.C., Yan, Y.Y.: A transition on minimum ignition energy for lean turbulent methane combustion in flamelet and distributed regimes. Proc. Combust. Inst. 31(1), 1401-1409 (2007)

26. Janicka, J., Kolbe, W., Kollmann, W.: Closure of the transport equation for the probability density function of turbulent scalar fields. J. Non-Equilib. Thermodyn. 4, 47-66 (1979)

27. Jaouen, N.: An automated approach to derive and optimise reduced chemical mechanisms for turbulent combustion. Ph.D. thesis, Normandy University, INSA Rouen Normandie (2016)

28. Jaouen, N., Vervisch, L., Domingo, P.: Auto-thermal reforming (ATR) of natural gas: An automated derivation of optimised reduced chemical schemes. Proc. Combust. Inst. 36(3), 3321-3330 (2017)

29. Jaouen, N., Vervisch, L., Domingo, P., Ribert, G.: Automatic reduction and optimisation of chemistry for turbulent combustion modeling: Impact of the canonical problem. Combust. Flame 175, 60-79 (2017)

30. Kariuki, J., Dawson, J.R., Mastorakos, E.: Measurements in turbulent premixed bluff body flames close to blow-off. Combust. Flame 159(8), 2589-2607 (2012)

31. Karlovitz, B.: Open turbulent flames. Symp. (Int.) Combust. 4(1), 60-67 (1953)

32. Karlovitz, B., Lewis, B.: Comment on the paper "Flame quenching by turbulence". Combust. Flame 54(1-3), 229 (1983)

33. Kerstein, A.R.: Hierarchical parcel-swapping representation of turbulent mixing. part 2. application to channel flow. J. Fluid Mech. 750, 421-463 (2014)

34. Lapointe, S., Blanquart, G.: Fuel and chemistry effects in high Karlovitz premixed turbulent flames. Combust. Flame 167, 294-307 (2016)

35. Lapointe, S., Savard, B., Blanquart, G.: Differential diffusion effects, distributed burning, and local extinctions in high Karlovitz premixed flames. Combust. Flame 162(9), 3341-3355 (2015)

36. Lele, S.K.: Compact finite difference schemes with spectral like resolution. J. Comput. Phys. 103, 16-42 (1992)

37. Libby, P.A.: Introduction to turbulence. Combustion. Taylor \& Francis (1996)

38. Liñán, A., Williams, F.A.: Fundamental aspects of combustion. Oxford University Press, Oxford, UK (1993)

39. Lu, T., Law, C.K.: A directed relation graph method for mechanism reduction. Proc. Combust. Inst. 30(1), 1333-1341 (2005)

40. Luche, J.: Elaboration of reduced kinetic models of combustion. application to the a kerosene mechanism. Ph.D. thesis, Orléans University (2003)

41. Luche, J., Reuillon, M., Boettner, J.C., Cathonnet, M.: Reduction of large detailed kinetic mechanisms: application to kerosene/air combustion. Combust. Sci. and Tech. 176(11), 1935-1963 (2004)

42. Meier, W., Weigand, P., Duan, X., Giezendanner-Thoben, R.: Detailed characterization of the dynamics of thermoacoustic pulsations in a lean premixed swirl flame. Combust. Flame 150(1/2), 2-26 (2007)

43. Moureau, V., Domingo, P., Vervisch, L.: From large-eddy simulation to direct numerical simulation of a lean premixed swirl flame: Filtered laminar flame-pdf modeling. Combust. Flame 158(7), 1340-1357 (2011)

44. Nomura, H., Murakoshi, T., Suganuma, Y., Ujiie, Y., Hashimoto, N., Nishida, H.: Microgravity experiments of fuel droplet evaporation in sub- and supercritical environments. Proc. Combust. Inst. 36(2), 2425 - 2432 (2017)

45. Pepiot, P., Pitsch, H.: An efficient error propagation based reduction method for large chemical kinetic mechanisms. Combust. Flame 154(1-2), $67-81$ (2008)

46. Peters, N.: Length scales in laminar and turbulent flames. In: E.S. Oran, J.A. Boris (eds.) Numerical approaches to Combustion Modeling, Prog. Astronautics and Aeronautics, vol. 135, pp. 155-182. AIAA, Washington DC (1991)

47. Peters, N.: Turbulent Combustion. Cambridge University Press (2000)

48. Peters, N.: Multiscale combustion and turbulence. Proc. Combust. Inst. 32(1), 1-25 (2009)

49. Poludnenko, A.Y., Oran, E.S.: The interaction fo high-speed turbulence with flames: Turbulent flame speed. Combust. Flame 158(2), 301-326 (2011) 
50. Ranjan, R., Muralidharan, B., Nagaoka, Y., Menon, S.: Subgrid-scale modeling of reaction-diffusion and scalar transport in turbulent premixed flames. Combust. Sci. Tech. 188(9), 1496-1537 (2016)

51. Savard, B., Blanquart, G.: Broken reaction zone and differential diffusion effects in high Karlovitz n-C7H16 premixed turbulent flames. Combust. Flame 162(5), 2020-2033 (2015)

52. Savard, B., Bobbitt, B., Blanquart, G.: Structure of a high Karlovitz n-C7H16 premixed turbulent flame. Proc. Combust. Inst. 35(2), 1377-1384 (2015)

53. Shepherd, I.G., Cheng, R.K., Plessing, T., Kortschik, C., Peters, N.: Premixed flame front structure in intense turbulence. Proc. Combust. Inst. 29(2), 1833-1840 (2002)

54. Shy, S.S., Liu, C.C., Lin, J.Y., Chen, L.L., Lipatnikov, A.N., Yang, S.I.: Correlations of high-pressure lean methane and syngas turbulent burning velocities: Effects of turbulent reynolds, Damköhler, and Karlovitz numbers. Proc. Combust. Inst. 35(2), 1509-1516 (2015)

55. Sirignano, W.A.: Fuel droplet vaporization and spray combustion theory. Prog. Energy Combust. Sci. 8, 291-322 (1983)

56. Sirignano, W.A.: Advances in droplet array combustion theory and modeling. Progress in Energy and Combustion Science 42, 54-86 (2014)

57. Sitte, M.P., Bach, E., Kariuki, J., Bauer, H.J., Mastorakos, E.: Simulations and experiments on the ignition probability in turbulent premixed bluff-body flames. Combust. Theory Modelling 20(3), 548-565 (2016)

58. Sjöholm, J., Rosell, J., Li, B., Richter, M., Li, Z., Bai, X.S., Aldén, M.: Simultaneous visualization of $\mathrm{OH}, \mathrm{CH}, \mathrm{CH} 2 \mathrm{O}$ and toluene $\mathrm{PLIF}$ in a methane jet flame with varying degrees of turbulence. Proc. Combust. Inst. 34(1), 1475-1482 (2013)

59. Spalding, D.B.: The combustion of liquid fuels. Symp. (Int.) on Combust. 4, 847-864 (1953)

60. Sundaram, B., Klimenko, A.Y., Cleary, M.J., Maas, U.: Prediction of NOx in premixed high-pressure lean methane flames with an MMC-partially stirred reactor. Proc. Combust. Inst. 35(2), 1517-1525 (2015)

61. Wang, H., Hawkes, E.R., Chen, J.H.: Turbulence-flame interactions in DNS of a laboratory high Karlovitz premixed turbulent jet flame. Phys. Fluids 28, 095,107 (2016)

62. Wang, H., Xu, R., Wang, K., Bowman, C.T., Hanson, R.K., Davidson, D.F., Brezinsky, K., Egolfopoulos, F.N.: A physics-based approach to modeling real-fuel combustion chemistry - I: Evidence from experiments, and thermodynamic, chemical kinetic and statistical considerations. Combust. Flame (in press). DOI 10.1016/j.combustflame. 2018.03.019

63. Wang, K., Ribert, G., Domingo, P., Vervisch, L.: Self-similar behavior and chemistry tabulation of burnt-gases diluted premixed flamelets including heat-loss. Combust. Theory and Modelling 4(14), 541-570 (2010)

64. Xu, J., Pope, S.: Pdf calculations of turbulent nonpremixed flames with local extinction. Combustion and Flame 123, 281-307 (2000)

65. Yang, S.I., Shy, S.S.: Global quenching of premixed CH4/air flames: Effects of turbulent straining, equivalence ratio, and radiative heat loss. Proc. Combust. Inst. 29(2), 1841$1847(2002)$

66. Yuen, F.T.C., Gülder, Ö.L.: Turbulent premixed flame front dynamics and implications for limits of flamelet hypothesis. Proc. Combust. Inst. 34(1), 1393-1400 (2013)

67. Zhou, B., Brackmann, C., Li, Q., Wang, Z., Petersson, P., Li, Z., Aldén, M., Bai, X.S. Distributed reactions in highly turbulent premixed methane/air flames: Part I. Flame structure characterization. Combust. Flame 162(7), 2937-2953 (2015)

68. Zhou, B., Brackmann, C., Li, Z., Aldén, M., Bai, X.S.: Simultaneous multi-species and temperature visualization of premixed flames in the distributed reaction zone regime. Proc. Combust. Inst. 35(2), 1409-1416 (2015)

69. Zhou, B., Brackmann, C., Wang, Z., Li, Z., Richter, M., Aldén, M., Bai, X.S.: Thin reaction zone and distributed reaction zone regimes in turbulent premixed methane/air flames: Scalar distributions and correlations. Combust. Flame 175, 220-236 (2017) 